\title{
Risk effects of the spread route of mycotoxins
}

\author{
Györgyi Biró -János Tamás -János Borbély -Lili Mézes -Gergely Hunyadi
}

University of Debrecen Centre of Agricultural and Applied Economic Sciences Faculty of Agricultural and Food Sciences and Environmental Management Department of Water and Environmental Management Department of Water and Environmental Management, Debrecen 4032 Böszörményi út 138. E-mail: gybiro@agr.unideb.hu

Keywords: Fusarium, mycotoxin, food chain, elimination

\section{SUMMARY}

In Hungary the mycotoxin is a great problem, because there are many natural toxins in wheat and maize. These cereals can be found on considerable proportion of the country's sowing area, and they are deterministic food for the population. The direct human and animal utilization of the contaminated cereals mean a serious risk in the food chain. In Hungary's climate the soil is contaminated with pathogen moulds, particularly Fusarium species, which increase by respective temperature and moisture content in cereals. The Fusarium can decrease the quality of the wheat in different ways: decrease the germination capability and cause visible discoloration and appearance of mould, reduces the dry material and nutrient content of the grain. From the toxins produced by the Fusarium genus, the trichotecene (T-2, HT-2, deoxinivalenol, nivalenol, diacetoxyscxirpenol, Fusarenon-X) and the estrogenic zearalenon (F-2) are the most common in Hungary. The fumonisins $\left(F B_{1}, F B_{2}, F B_{3}\right)$ first identified in 1988, relatively newly discovered, are also important. Major proportion of mycotoxins in a healthy organization is metabolized by the enzyme system of liver and intestinal bacteria. The toxicity is reduced or even leaves off. However, more toxic and biologically active compounds can be formed. For the reduction of mycotoxin-contamination several possibilities are available in the case of storage, processing and feeding.

\section{ABSTRACT}

The Fusarium species belong to the conidia forming Deuteromycetes class. Fuckel called this class Fungi imperfecti, which designating is still widely used these days. Only their asexual form of reproduction is known, meaning that this group of fungus produces asexual spores (ascospores or basidiospores). The organization is based on the asexual spores, most commonly end of the micelia or distinct, strong bracket-shaped holders are produced. The shapes, color, method of formation of conidia are very diverse. Usually there are short-lived with very thin cell-walls. They are formed in large numbers; primarily serve the rapid spread of the species. The Fusarium genus classified as Moniliales order and Tuberculariacea family, which creates several asexual spores. Such as the crescent or sickle-shaped macroconidium with typical base-cell and structured multicellular crosswall, or the curved sausage-formed, 1-2 celled microconidium. In addition, some species can even create clamidospore or sclerocium (Mudich, 1988).

\section{INTRODUCTION}

Respect of phytopathology one of the most significant filiform fungus is the $F$. graminearum. It causes ear, root and stem rot by several important cultivated plant. It can be separated to two biologically different groups. The first biological group is soil originated, which cause stem rot on wheat and other cereals. This group is heterothallic, never creates fruiting bodies. The second biological group infects and spreads by air, causes ear rot and head blight on wheat and maize. This group of individuals is homothallic, creates plenty of fruiting bodies in open field and under laboratory conditions (Szécsi, 1994). Respect of phytopathology and mycotoxicology $F$. verticillioides ( $F$. moniliforme) is also meaningful. In European countries $90 \%$ of the maize grain yield damage caused by fungal infections (Szécsi et al., 1995) - however, a number of Fusarium species produce head blight. In Hungary 16 species have been identified, but around the world there are many species - mentioned in literature. In the warmer regions the $F$. graminearum is the dominant species. $F$. culmorum, $F$. avenaceum, sometimes Microdochium (Fusarium) nivale are common in the colder areas. The epidemic dynamics of maize is different from the wheat. Rainy, wet weather rather promotes the $F$. graminearum infection. In drier weather $F$. verticillioides is the dominant, and the infestation also increases the problem of $F$. verticillioides (Mesterházy, 2010).

\section{SPREAD ROUTE}

The beginning of modern „mycotoxin research” can be put around the beginning of 1960, when in Great Britain described the so-called „X-disease” (turkey X disease), when more than 100,000 turkeys had been 
destroyed (Blount, 1961). The cause of the epidemic aflatoxin produced by Aspergillus flavus was identified (Liener, 1969). In these days, more than 400 different chemical structures, mode of action and toxicity of mycotoxins have been discovered and described (Gareis et al., 1989). In Hungary the importance of various Fusarium mycotoxins were determined: the oestrogen zearalenone, the fumonisins and the trichotecene mycotoxins (Rafael et al., 1998). In Hungary and the temperate zone the DON, the T-2 trichotecene mycotoxins are the most common in grains, - used for feed (Placinta et al., 1999). It is well-known, that on the climate of Hungary the soil is infected by pathogens, moulds, primarily Fusarium species, which in cereals can multiply depending on the temperature and humidity. Their secondary metabolites, the mycotoxins may get through the food chain (plant-animal-human) to the animal and/or the human body (Barna-Vetró et al., 1997). The hazard still cannot be estimated accurately.

Mycotoxins enter directly with vegetable and consumer products into the human body. In Hungary the mycotoxin problem is so important, because the natural toxins mainly can be found in those cereals (wheat, maize), that give the main proportion of the country's arable lands. It serves the main food of the population (Kovács, 2010). In case of the Fusarium the DON is a „,marker” toxin. If the DON appears, it certainly was a Fusarium infection, moreover in many cases there are the zearalenone and the other trichothecene toxins (most of them occurring in the T-2 toxin) too. The zearalenon and the trichothecene toxins appear in a lower level of magnitude as the DON toxin (Búza and M. Schill, 2010).

A large part of mycotoxins enters through the intestinal tract to the human body. After absorption from the ilium these toxins get through the portal circulation to the liver. Hence can be excreted unchanged with the bile and eliminated with the faeces from the body. The liver can convert or cumulate the toxins. The toxins can be detected from the liver through the circulation to the various organs (e.g. kidney, muscle, adipose tissue, brain) or excreted (e.g. urine, milk). The significant proportion of mycotoxins is metabolized by the enzyme system of the liver and the intestinal bacteria. The toxicity may be reduced or even leave off, or can be formed to more toxic, biologically active metabolites than the starting molecule (e.g. the transformation of zearalenone into $\alpha$ zearalenol) (Kovács, 2010).

In the feed the presence of mycotoxins represents a serious threat, so in many countries there is a limitation value. The guidance values of the European Union are shown Table 1. (Búza and M. Schill, 2010).

Guidance values on the presence of deoxynivalenol, zearalenone and fumonisins in products intended for animal feeding

\begin{tabular}{|c|c|c|}
\hline $\begin{array}{l}\text { Mycotoxin Products } \\
\text { intended for animal feed }\end{array}$ & Products intended for animal feed & $\begin{array}{l}\text { Guidance value in } \mathrm{mg} / \mathrm{kg}(\mathrm{ppm}) \\
\text { relative to a feedingstuff with a } \\
\text { moisture content of } 12 \%\end{array}$ \\
\hline \multirow[t]{6}{*}{ Deoxynivalenol } & Feed materials: & \\
\hline & Cereals and cereal products with the exception of maize by-products & 8 \\
\hline & Maize by-products & 12 \\
\hline & Complementary and complete feedingstuffs with the exception of: & 5 \\
\hline & Complementary and complete feedingstuffs for pigs & 0.9 \\
\hline & $\begin{array}{l}\text { Complementary and complete feedingstuffs for calves ( }<4 \text { months), } \\
\text { lambs and kids }\end{array}$ & 2 \\
\hline \multirow[t]{7}{*}{ Zearalenone } & Feed materials: & \\
\hline & Cereals and cereal products with the exception of maize by-products & ? \\
\hline & Maize by-products & 3 \\
\hline & Complementary and complete feedingstuffs: & \\
\hline & $\begin{array}{l}\text { Complementary and complete feedingstuffs for piglets and gilts (young } \\
\text { sows) }\end{array}$ & 0.1 \\
\hline & Complementary and complete feedingstuffs for sows and fattening pigs & 0.25 \\
\hline & $\begin{array}{l}\text { Complementary and complete feedingstuffs for calves, dairy cattle, sheep } \\
\text { (including lamb) and goats (including kids) }\end{array}$ & 0.5 \\
\hline \multirow[t]{7}{*}{ Fumonisin B1 + B2 } & Feed materials: & \\
\hline & Maize and maize products & 60 \\
\hline & Complementary and complete feedingstuffs for: & \\
\hline & Pigs, horses (Equidae), rabbits and pet animals 5 & 5 \\
\hline & Fish & 10 \\
\hline & Poultry, calves ( $<4$ months), lambs and kids & 20 \\
\hline & Adult ruminants ( $>4$ months) and mink & 50 \\
\hline
\end{tabular}


The national recommendations are stricter: animal species $0.4-2.0 \mathrm{mg} / \mathrm{kg}$ in case of the DON and $50-30$ $\mathrm{mg} / \mathrm{kg}$ in case of fumonisins. In case of T-2 toxin there is just national recommendations (Institute of Veterinary Science Committee) for complementary and complete feedingstuffs: animal species 0.25-0.8 mg/kg (Búza és M. Schill, 2010).

In the practical life determines the Fusarium infection the MSZ 6383:1998. standard can be used. According to the standard the grain is impaired by the Fusarium sp., in which can be seen pink or whitish mould colonies. The grain fades, degrades and easily crumbled. The contamination of microorganisms is a considerable problem that may occur significant deterioration in quality of grain or accumulation of some toxins. The gas chromatography has a main role in the determination of Fusarium toxins since 1980s. Today the high performance (intensive) liquid chromatography (HPLC) is widely used. In the mycotoxin analytics the latest tendency is the immunodiagnostic methods (ELISA). We can use specific antibodies, which allow highly selective separation and subsequently a very sensitive and reliable quantification (Borbély et al., 1999).

\section{TOXICITY}

Mycotoxins have extremely diverse chemical structures (some examples show on Figure 1.). Accordingly, they may cause wide variety of symptoms and illnesses (Kovács, 2010). In case of the trichotecene mycotoxins the toxicity's base is the presence of the 12,13-epoxide ring. The "A" type trichithecenes does not contain any keto-group on the 8.C-atom. This group includes the T-2, the HT-2, the diacetoxiszcirpenol (DAS) and the neoszolaniol (NEO) toxins. However, the "B"type trichothecenes contain a keto-group on the 8.C-atom. This group includes the deoxynivalenol (DON), the nivalenol (NIV) and the fusarenon-X (FX)(Mézes and Balogh, 2010). The zearalenone is a rezolcil acid lactone derivative. The family of zearalenone involves more, oestrogenlike compounds. However, these have different oestrogenic effect. During the metabolism of ZEA $\alpha$-zearalenole forms in pigs and humans. The $\alpha$-zearalenol has four times stronger oestrogen-like effect than the zearalenone (Cseh and Kovács, 2010). The fumonisin $B_{1}$ is a polar compound, which's base is a long carbon chain with hydroxyl- and methyl-groups. Twelve of the known fumonisin differ from each other in the carbon chain groups (Szabó and Kovács, 2010).

Today the biological mechanisms of the main toxins are well-known. On the first step the deoxynivalenol inhibits the protein synthesis, unbalances the cytokinin regulation, changes the cell proliferation and causes cell death. It is a very strong immune-system inhibitor. The T-2 toxin is also a very strong protein-synthesis inhibitor. It creates transient $\mathrm{Ca}^{2+}$ ions, activates endonucleases and causes cell death. It can be seen that the listed toxins work in very different ways. Fumonisins inhibit the synthesis of ceramides from sphinganin, blocking the biosynthesis of sphingolipid complexes. The quantity of sphinganins increases and the recycling of sphingosins is blocked, resulting in cell dysfunction followed by cell death. The zearalenone binds to the oestrogen receptors and produces oestrogen response. It throws the balance of sex hormones. The ZEA often causes ovary and uterus swelling, anteflexion of the uterus and abortion (Riley, 1998).

Figure 1.: Chemical structures of some important mycotoxins

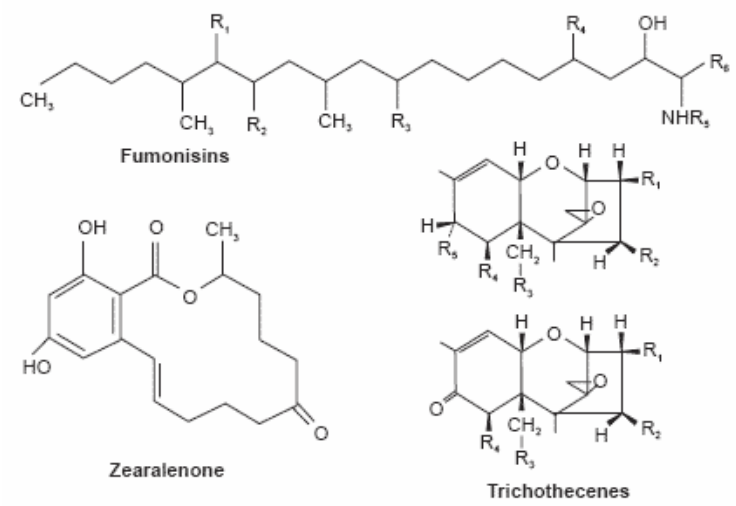

Source: folowing Dawson, 2006.

\section{HUMAN- AND ANIMAL HEALTH EFFECTS}

Mycotoxins have low molecular weight, have not got antigen effect, thus vaccine cannot be made from them. They are unsensitive to high temperature, because the $100-200^{\circ} \mathrm{C}$ dried cereals may contain several toxins. They can resist the hydrochloric gastric acid, so their toxic properties can stay in the organism. They are aggressive cytotoxins that accumulate in various organs of the body (liver, kidney) and directly or indirectly inhibit the body's specific defense mechanisms. Mycotoxins can get into various animal origin foods (milk, egg, blood and liver). It is now known that many of them risk directly animal and human health. In the food chain the presence 
of toxins should be counted everywhere, where there is possibility for proliferation of Fusarium. The mycotoxins have micro quantity in the food chain. Nowadays the chronic poisoning and multitoxic damages are more common. The horizontal and vertical movement of toxins can be detected from the soil through the human food to the breast-milk (Kovács, 2010).

Fusarium toxins that have carcinogenic effect are the fumonisins. The trichothecenes take expressly immunosuppressive effect. The trichothecenes and the zearalenone affect the reproduction. The fumonisins and the trichothecenes have detrimental effect to the nervous system. External and internal factors influence the mycotoxin's effects: the chemical structure of the mycotoxin (cumulation), concentration and period of effect, simultaneous presence of several mycotoxins (interaction, synergism, additionality effect), individual susceptibility and state of health (Kovács, 2010).

The trichothecene toxins (T-2, HT-2, DON, DAS, NIV and Fusarenon-X) are most common in Hungary. Among them the deoxynivalenol (DON) occurs most often in the different cereals and their products. The trichotecenes cause severe gastrointestinal disturbances (emesis, diarrhea). They are dermatotoxic and immunsuppressive, affect the reproductive function, modify the suprarenal gland function, induce necrotic and inflammatory process, and cause nerve lesions. They inhibit the protein, DNA and RNA synthesis, affect the membrane transport processes.

The zearalenone (ZEA, F-2 toxin) is an oestrogenic toxin, bind to oestrogen receptors and causes organs damage. In male animals it inhibits the spermiogenesis. In females in the permanent oedema state of uterus is detected with considerable cell proliferation. It causes ovarian and uterine asincrone. The implantation of ovum is prevented, uterine origin infertility may occur. The zearalenone may cause the sexual prematurity in girls (Kovács, 2010). The pig is the most sensitive species of animals to ZEA. In contrast, the cattle are less sensitive to that toxin (Cseh and Kovács, 2010). Recently, the zearalenone connect with the carcinogenesis of oestrogendependent tissues (Kovács, 2010).

The fumonisins of the Fusarium toxins are relatively newly-discovered, in 1988 described their group. The group's main member is the fumonisin $\mathrm{B}_{1}$. It causes different clinical appearance in species of animals: in horses encephalomalacia and in pigs pulmonary oedema (Placinta et al., 1999). It belongs to the IARC 2B classification group on the basis of carcinogenic effect that is a potentially carcinogenic. High $\mathrm{FB}_{1}$ containing maize is responsible for the development of human esophageal cancer. In addition, the toxin causes confusion by the neural tube's development in the fetus (Kovács, 2010). The main Fusarium species and their mycotoxins are summarized in Table 2.

Table 2.

Occurrence of Fusarium species and their mycotoxins in cereals

\begin{tabular}{|c|c|c|c|}
\hline Fusarium species & $\begin{array}{l}\text { Occurence in } \\
\text { cereals }\end{array}$ & Infectivity on ears & Mycotoxins \\
\hline F. graminearum & +++++ & strong & DON, 3AcDON, 15AcDON, NIV, ZON, DeDON \\
\hline F. culmorum & ++ & strong & DON, 3AcDON, NIV, ZON, \\
\hline F. avenaceum & +++ & moderate & MON \\
\hline F. crookwellense & ++ & strong & NIV, FUS, ZON \\
\hline F. poae & +++ & moderate & NIV, FUS \\
\hline F. sporotrichioides & ++ & moderate & T-2, HT-2, NEO \\
\hline F. tricinctum & + & low & MON \\
\hline F. chlamydosporum & + & low ${ }^{\mathrm{m}}$ & MON \\
\hline F. semitectum & + & saprophytic & BEA \\
\hline F. equiseti & ++ & saprophytic & FUCH, ZON \\
\hline F. acuminatum & + & low & T-2, MON \\
\hline F. moniliforme & $++++^{\mathrm{m}}$ & moderate $^{\mathrm{m}}$ & $\mathrm{FB}_{1}, \mathrm{FB}_{2,} \mathrm{FB}_{3}, \mathrm{FU}-\mathrm{C}$ \\
\hline F. subglutinans & $+++++^{\mathrm{m}}$ & moderate & MON, BEA, FUP \\
\hline F. proliferatum & $++^{\mathrm{m}}$ & low & $\mathrm{FB}_{1}, \mathrm{FB}_{2}, \mathrm{MON}, \mathrm{BEA}, \mathrm{FUS}$ \\
\hline F. anthophilum & $+{ }^{\mathrm{m}}$ & saprophytic & MON \\
\hline F. solani & ++ & saprophytic & MON \\
\hline F. oxysporum & ++ & saprophytic & MON \\
\hline Microdochium nivale & +++ & moderate & - \\
\hline
\end{tabular}

Source: following Mesterházy, 2002.

Occurence: +++++ very common, ++++ common, +++ intermediate, ++ rare, + very rare, ${ }^{\mathrm{m}}$ on maize

Shortening: DON: deoxynivalenol, AcDON: acetyl deoxynivalenol, NIV: nivalenol, ZON: zearalenon, DeDON: dideoxynivalenol, MON: moniliformin, FUS: fusarenon, NEO: neosolaniol, BEA: beauvericin, FUCH: fusarochromanon, FB: fumonisin B, FU-C: fusarin C, FUP: Fusaproliferin, T-2: T-2 toxin, HT-2: HT-2 toxin 


\section{REDUCTION OF ENVIRONMENTAL RISKS OF TOXICITY}

The reduction of mycotoxin contamination a number of options are available. During the storage of materials the mould's reproduction, the mycotoxin's production can be regulated with humidity and temperature control. In the case of transport and harvesting the mould's infection is reducible further with continuous disinfection of the transport vehicle, the storage space and the delivery system. For that purpose we can use sodium hypochlorite washing. Selection of damaged grains, elimination of the glume leaves and other contaminations also have efficient manner. We can use mould inhibit materials, such as the propionid acid. The lactic-acid bacteria (Lactobacillus coryniformis, L. plantarum or Pediococcus pentosaceus) can reduce the contamination of mycotoxins in forage, which inhibits the growth of Fusarium species. The nucleotides $(10 \mathrm{mg} / \mathrm{kg}$ feed) are effective in the presence of deoxynivalenol and T-2 toxin, which cause DNA damage by poultry. The Fusarium species produces anti-thiamine factor, therefore feed's thiamine supplement is beneficial too. In addition, some antioxidant mixtures have proven effective some Fusarium mycotoxins, such as fumonisin $\mathrm{B}_{1}, \mathrm{~T}-2$ toxin and zearalenone toxin. Using mycotoxin-binding activated carbon has been known for long, although in the practice is not widespread. Although the activated carbon has a large active surface area $\left(500-3500 \mathrm{~m}^{2} / \mathrm{g}\right)$, but the effectiveness can influence the carbon's particle size, active surface, the chemical structure of the mycotoxin and the contamination's rate. The activated carbon effectively binds the deoxynivalenol, the nivalenol, the fumonisins and the T-2 toxin produced by Fusarium species. However, only it affect in large dose $(50-200 \mathrm{~g} / \mathrm{kg}$ feed) significantly. From clay mineral the betonite is suitable for neutralization of T-2 toxin's unfavourable effect. The carbon-based mycotoxin-binding polymer is the cholestyramine. This is a synthetic anion exchange resin, which binds to the zearalenone and fumonisins in vitro. The high roughage content of feed has also mycotoxin-binding capacity, which is known, primarily in horse feeding. However, the medick hay and the wheat straw can also be infected with Fusarium moulds, so that may be potential sources of mycotoxins (Mézes et al., 2010).

The new direction of mycotoxin's protect is the biotransformation, which is based the enzymes of microorganisms, live in the soil, the yeast, or the rumen, that can metabolize effectively certain mycotoxins. For example, in the trichotecene toxin's ring structure there is a 12,13-epoxide group, which is responsible for the toxic's activity. Reduction of the epoxide group is well-known process by the microbial epoxidase enzyme of the ruminant animals. Nowadays many species of bacteria and yeast are well-known, which have similar activity. For example, the Eubacterium intestinal bacteria may produce also epoxidase, which is capable efficiently for the 12,13-epoxide ring's de-epoxidation, so the trichotecene mycotoxins may become non-toxic or less toxic metabolites (Mézes et al., 2010).

The items unfit for consumption or animal feed can be used up alcohol production. In several countries (e.g. in Brazil) are already massive ethanol production, which can be used in cars. The technology is given, in Szabadegyház there is a maize based factory. However, the by-products of alcohol can cause problems here. According to Austrian attempts the energy content of wheat corresponds to medium quality coal. In the course of the technology the organic materials are consumed, such as the mycotoxins, so it can be an effective way to solve the problem. In the West, particularly in America, numerous industrial processing options are known, no food or feed orientation (Mesterházy, 2002).

Alternative solution can be the Fusarium infected cereal's utilization for biogas production. It spells danger the anaerobic fermentation process, excessive input may be toxic. If you are setting up biological analogy between the bovine digestion and the life cycle of biogas-producing anaerobic bacteria, then this risk to exists the micro-organisms of biogas production. The principle of biotransformation may prove effectively the mycotoxin's neutralzation in the biogas production.

\section{REFERENCES}

Barna-Vetró I.-Solti L.-Gyöngyösiné H. Á.-Szabó J.-Wölfling A. (1997): Immundiagnostics for mycotoxin determination. Hungarian Agricultural Research, 6.16-19.

Blount W. P. (1961): Turkey „X” disease. J. Br. Turkey Fed. 9.52-54.

Borbély M.-Veres E. -Györi Z. (1999): Screening for mycotoxin contamination of wheat harvested in 1998. 17 ${ }^{\text {th }}$. ICC, Conference. Abstracts Book, 27.

Búza L.-M.Schill J. (2010): Test methods, results of mycotoxins in the occurrence of domestic feed. In: News of the mycotoxin research (edited by Kovács M.). Kaposvár,13-20.

Cseh S.-Kovács M. (2010): Effects of mycotoxins on reproduction. In: News of the mycotoxin research (edited by Kovács M.). Kaposvár,73-84.

Dawson K. A.-Evans J.-Kudupoje M. (2006): Understanding the adsorption characteristics of yeast cell wall preparations associated with mycotoxin binding. In: Lyons TP, Jacques KA, eds. Science and Technology in the Feed Industry. Nottingham, 169-181.

Gareis M. -Bauer J.-Enders C.-Gedek, B. (1989): Contamination of cereals and other feed with Fusarium mycotoxins in European countries. In: Chelkowski, J. ed. Fusarium, Mycotoxins, Taxonomy and Pathogenicity. Elsevier, Amsterdam, 441-472. 
Kovács F. (2010): Agricultural production - Food chain - Mycotoxins. In: News of the mycotoxin research (edited by Kovács M.). Kaposvár, 7-12.

Kovács M. (2010): The human-health aspects of mycotoxins. In: News of the mycotoxin research (edited by Kovács M.). Kaposvár, 85102.

Liener I. E. (1969): Toxic constituents of plant foodstuffs. Academic Press, New York, 392-394.

Mesterházy Á. (2002): Mycotoxins, food safety, the potential solution. htpp://www.kfki.hu/ cheminfo/osztaly/eloadas/mesterhazya.html Mesterházy Á. (2010): Possibilities of elimination of mycotoxins in food chain and the resistance improvement. In: News of the mycotoxin research (edited by Kovács M.). Kaposvár, 119-140.

Mézes M.-Balogh K. (2010): Mycotoxins' effects the body's antioxidant system and the lipid peroxidation's processes. In: News of the mycotoxin research (edited by Kovács M.). Kaposvár, 59-71.

Mudich A. (1988): Plant protection mycology. University of Keszthely Centre of Agricultural, Keszthely.

Placinta C.M-D'Mello J.P.F.-Macdonald A.M.C. (1999): A review of worldwide contamination of cereal grains and animal feed with Fusarium mycotoxins. Animal Feed Science and Technology, 78.1.21-37(17).

Rafai, P.-Bata A.-Papp Z.-Glavits, R. (1998): Effects of T-2 toxin contaminated feeds on the health and production of duck. Proc. 10th Eur. Poultry Conference, Jerusalem, Vol. I. 342-346.

Riley, R. T. (1998): Mechanistic interactions of mycotoxins: theoretical considerations. In: Sinha K. K. and Bhatnagar, D. (Eds.) Mycotoxins in agriculture and food safety. 227-253.

Szabó-Fodor J.-Kovács M. (2010): Metabolism, accumulation and elimination of fumonisin $B_{1}$ in pigs. In: News of the mycotoxin research (edited by Kovács M.). Kaposvár, 21-35.

Szécsi Á. (1994): Fusarium graminearum isolates were identified by a new method. Növényvédelem, 30.1.1-6.

Szécsi Á.-Vágújfalvi A. (1995): Detection of fumonisin mycotoxins in Fusarium moniliforme and Fusarium proliferatum cultures with ELISA. Növényvédelem, 31.7.317-321. 